\title{
Hang-up analysis and modelling for Cadia East PC1-S1 and PC2-S1
}

\author{
R Castro Advanced Mining Technology Center, University of Chile, Chile \\ D Cuello Newcrest Mining Limited, Australia
}

\begin{abstract}
Cadia Valley operations is a gold-copper deposit located in Orange, New South Wales, Australia. Currently, two macroblocks are in production - PC1-S1 and PC2-S1 of Cadia East at undercut levels 4670 and 4475, respectively. The production rate during 2016 reached approximately 43 ktonne/day for PC1 and 19 ktonne/day for PC2. These macroblocks have implemented different variants of the block caving method and have different rock mass characteristics and depth. The PC1-S1 block was subjected to intensive preconditioning, hydraulic fracturing (from Gallery 5050) and DDE (blasting), for a column height of $400 \mathrm{~m}$ from the production level (4650 $\mathrm{mRL}$ ). Finally, to propagate the caving effectively to surface, hydraulic fracturing was performed at $500 \mathrm{~m}$ below surface (maximum-depth hole). PC2-S1 was preconditioned only by hydraulic fracturing and is located $194 \mathrm{~m}$ below PC1.

These two macroblocks are at different stages of maturity. PC1, a mature cave, has shown a fine fragmentation, which diminished notably as the cave back reached the surface in 2014. Consequently, there have been few observed hang-ups, resulting in a high production rate when compared to caving standards. On the other hand, $P C 2$ has caving in progress and has shown a coarser fragmentation, and a large number of hang-ups. Therefore, prediction capabilities for hang-ups for PC2 is critical for planning purposes.

In order to understand and model hang-ups for PC2, a BCRisk ${ }^{\circledR}$ model was built. BCRisk is a methodology to assess key gravity flow-related risks based on logistic regression. A BCRisk model of hang-ups delivers the probability $(P)$ that the hang-up rate (HUR) would exceed 1 event/1,000 tonnes, that is $P(H U R>1)$. A univariate statistical analysis indicated that the key variables to be considered were the accumulated draw height $(m)$, the uniformity draw index and the rock mass rating (RMR). The same analysis indicated that the different lithologies observed at PC2 were not a key variable. Each of the key variables has a significant and relative impact on $P(H U R>1)$. An increase of $10 \mathrm{~m}$ on the draw height decreases the probability of hang-ups by $26 \%$, an increase of the RMR in 10 units increases the probability by $30 \%$, while an improvement of draw uniformity index (by $30 \%$ ) decreases the probability by $13 \%$.
\end{abstract}

The $P(H U R>1)$ was compared to the hang-ups database of $P C 2$ (which consider hang-up events measured during 2016). The model showed a good fit to the data with an $81 \%$ accuracy at predicting events in terms of the number of drawpoints and the percentage of active area that could present hang-up issues.

Keywords: fragmentation, hang-up events, statistical modelling, mine data

\section{Introduction}

Block caving is an underground mining method that involves undermining an orebody, allowing it to progressively collapse under its own weight. The caving process produces fragmentation of the block, which depends on several variables including the rock mass characteristics and the stress conditions. The estimation of fragmentation is a key aspect in caving operations because the occurrence of coarse fragmentation in drawpoints could produce loss in the operational continuity due to drawpoint hang-ups.

Hang-ups at drawpoints are arches formed by rocks of different sizes that can block the flow of fragmented rock. Hang-ups can be produced by obstruction of coarse material (mechanical arches) as well as by the compaction of fine material (Kvapil 2008). Hang-ups have a large impact on operations due to the flow 
interruption at the drawpoints, which affects drawpoint availability and, therefore, production rates and costs. Furthermore, with the objective that the sector in operation reaches the daily production target, ore is extracted from drawpoints with better fragmentation conditions. When there are differences in fragmentation, the uniformity of extraction in the sector decreases, which increases the probability of early dilution (Laubscher 1994; Susaeta 2004; Arancibia et al. 2018). This scenario makes hang-up prediction all the more necessary.

Modelling hang-ups is a complex task due to the large number of variables involved (Kvapil 2008). In block caving mines, it is common to first estimate fragmentation and to predict the hang-up rate (HUR) according to the proposed mining design (Brzovic et al. 2016). Furthermore, while hang-ups are related to fragmentation, this phenomenon is apparently quite random in nature as has been observed in controlled experiments (Lopez 2016). For this reason, resolving the fragmentation issue does not resolve the predictability of hang-ups.

In this study, instead of trying to conduct a fragmentation analysis as conducted by Brunton et al. (2016), a study of the extraction and hang-ups databases collected from Cadia East was analysed and modelled. First, a detailed statistical analysis of the hang-ups and fragmentation data from Cadia East PC1-S1 and PC2-S1 was conducted, followed by a probabilistic modelling of hang-ups using regression analysis techniques.

\section{$2 \quad$ Mine site}

Cadia Valley Operations is a gold-copper deposit that was discovered in 1994. It is located approximately $25 \mathrm{~km}$ from the city of Orange in central west New South Wales, and is $250 \mathrm{~km}$ west of Sydney (Figure 1).

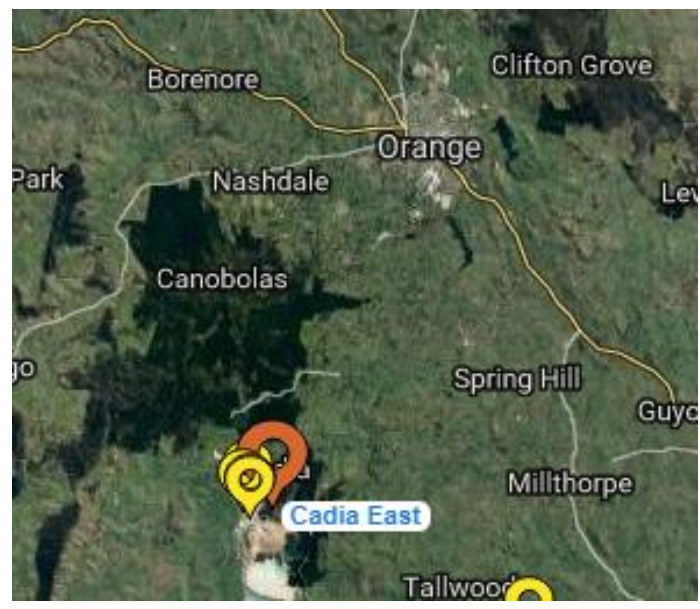

Figure 1 Cadia East location

The deposit consists of four macroblocks - PC1-S1, PC1-S2, PC2-S1 and PC2-S2 as shown in Figure 2.

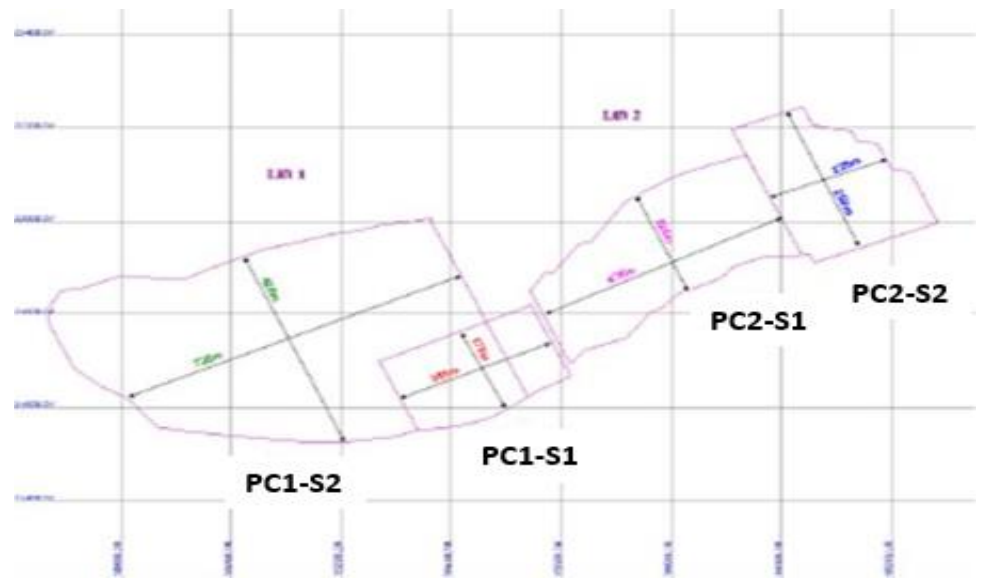

Figure 2 Plan view of Cadia East 
These blocks have used different variants of the block caving method (Figure 3). PC1-S1 block was subjected to intensive preconditioning, hydraulic fracturing (from Gallery 5050) and DDE (blasting), for a column height of $400 \mathrm{~m}$ from the production level $(4650 \mathrm{mRL})$. Finally, to propagate the caving effectively to surface, a surface hydraulic fracturing was performed to $500 \mathrm{~m}$ below surface (maximum-depth hole). PC2-S1 was preconditioned by hydraulic fracturing only (Lowther et al. 2016).

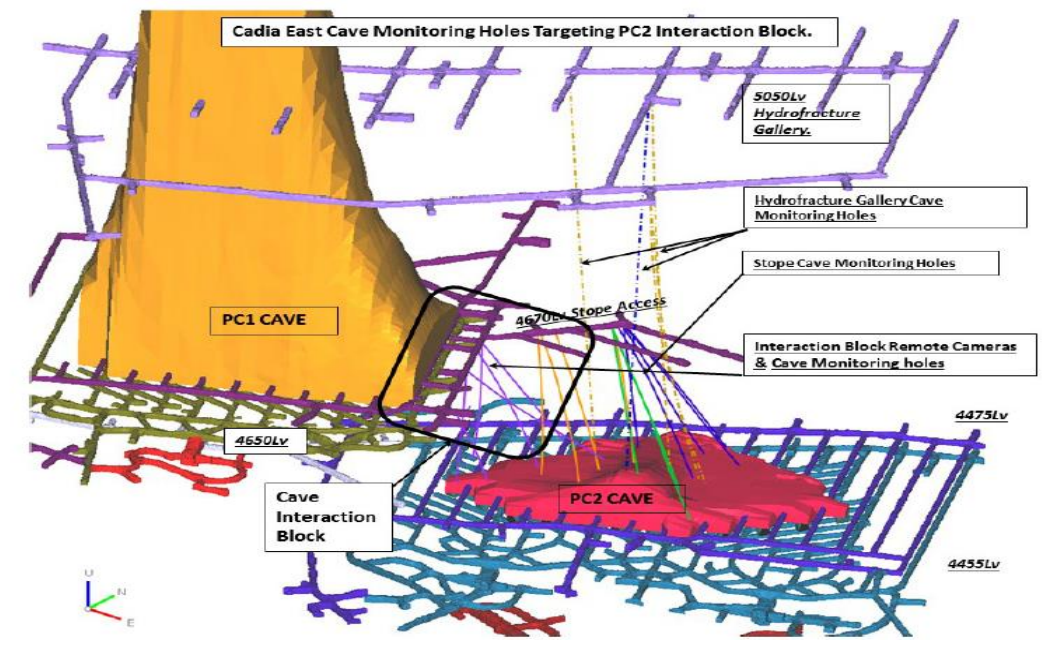

Figure 3 Cadia East PC1-S1 and PC2-S1 footprints (Lett et al. 2016)

The production level layouts are shown in Figure 4. For PC1-S1, the drawpoint spacing at the production level is $16 \times 20 \mathrm{~m}$. The total number of drawpoints on the block is 218 (10 production drifts, from 100 to 118). Of these, 10 correspond to single drawpoints located at the west side of the block. For PC2-S1, the spacing of the production level is $16 \times 20 \mathrm{~m}$. The total number of drawpoints is 318 . Figure 4(b) shows that the drawbell drift has two orientations on the block corresponding to the west and east of the 216 Production Drift. There are 12 isolated drawpoints, and they are located on the east side of the block.

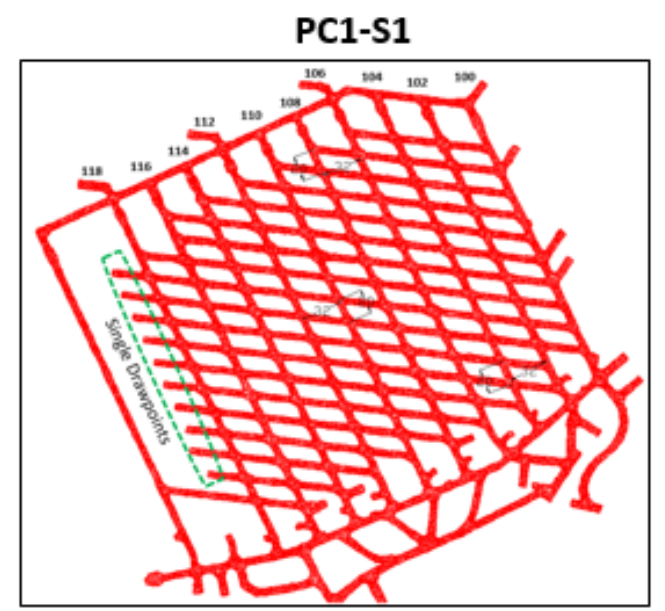

(a)

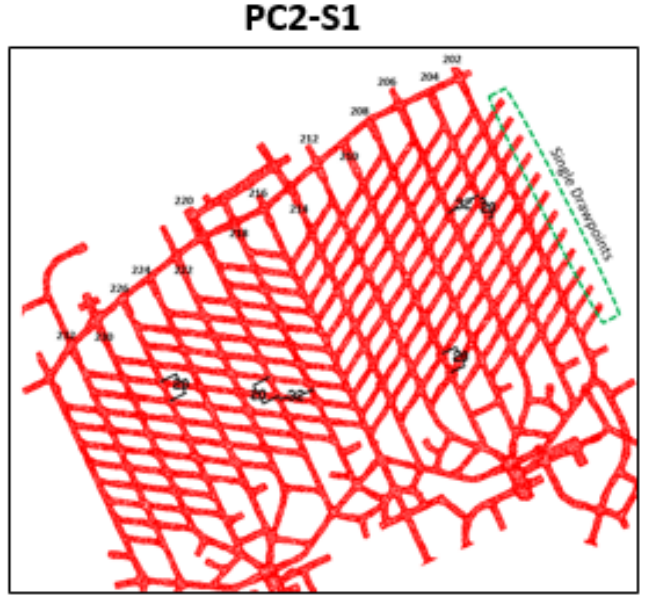

(b)

Figure 4 Production level at Cadia East - (a) PC1-S1; and, PC2-S1 (b) 
Finally, the rock mass properties are shown in Table 1. As shown, the rock mass at Cadia is competent with compressive strength reaching 146 to $156 \mathrm{MPa}$ (Lett \& Rossimel 2012; Lett 2016).

Table 1 Rock mass properties for Cadia East

\begin{tabular}{ll|l}
\hline Mine & Cadia East & \\
Rock & Volcanic & Monzonite \\
Unconfined compressive strength (UCS) & $146 \mathrm{mpa}$ & $152 \mathrm{mpa}$ \\
FF/m & $2-4$ & $2.5-4$ \\
Type of preconditioning & PC1 intensive/PC2 hydraulic fracturing \\
\hline
\end{tabular}

Figure 5 shows the distribution of the type of lithology per drawpoint at the production level at PC1 and PC2. As shown, there are two types of lithology - monzonite and volcanics being, in both cases, equally distributed in the footprint.

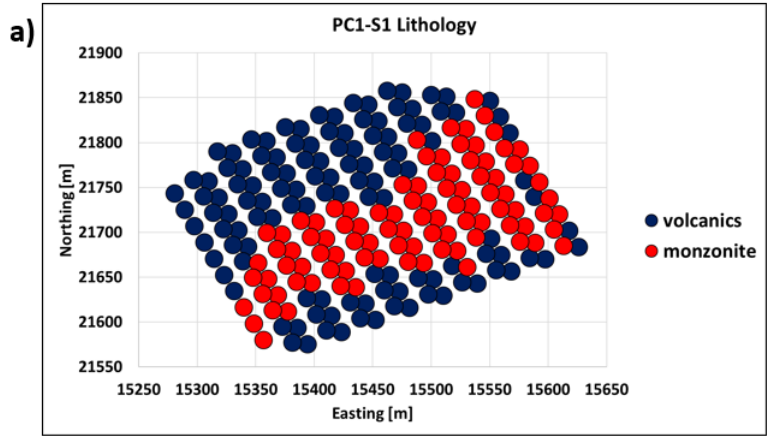

(a)

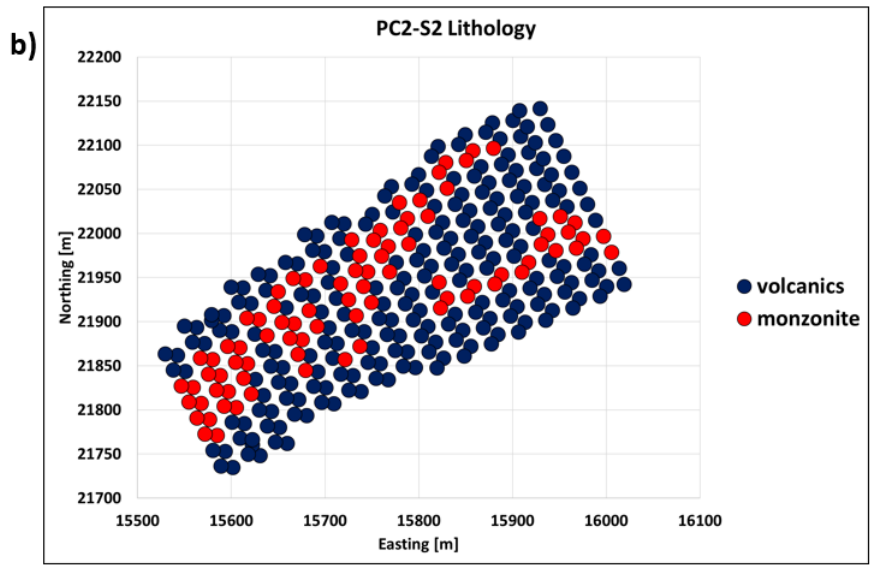

(b)

Figure 5 Plan view at the production level indicating the different lithologies observed at (a) PC1-S1; and, (b) PC2-S1

In conclusion, there were some differences between the Cadia Valley Operations (CVO) panels. The next step was to evaluate their differences in terms of fragmentation and hang-ups. These differences include the type of preconditioning and undercutting strategy used.

\section{Statistical analysis of hang-ups and fragmentation database for Cadia East}

An analysis was performed on the extraction database, hang-ups and fragmentation reported by drawpoints. Then, the most relevant variables were identified to construct a database in order to deliver a predictive operational model of hang-ups. The analysis was related to draw height $(\mathrm{m})$ or extraction percentage per drawpoint using the relationship:

$$
\text { Height of draw }=\frac{\text { Accumulated tonnage per drawpoint }}{\text { Area drawpoint } * \text { density }}
$$

Where the assumptions made were that the density is constant at $2.7 \mathrm{t} / \mathrm{m}^{3}$ and the area of influence of drawpoint $16 \times 20 \mathrm{~m}\left(320 \mathrm{~m}^{2}\right)$ is obtained:

$$
\% \text { Extraction per drawpoint }=\frac{\text { Accumulated tonnage per drawpoint }}{320 m^{2} * 1,000 * 2.7 \frac{\text { tonne }}{m^{3}}}
$$




$$
\begin{gathered}
\text { Draw rate }=\frac{\text { tonnage }}{m^{2}-d a y} \\
\text { Hang ups Rate }(\text { HUR })=\frac{\text { Number Events }}{1,000 \text { tonnes }}
\end{gathered}
$$

Figure 6 shows the extraction percentage per drawpoint for PC1-S1, and Figure 7 for PC2-S1. For PC1, it is noted that at the centre of the block, extraction reached at least $40 \%$, while at the borders, extraction remains at a range of $10-20 \%$. The mean extraction from the block is $23 \% \pm 8 \%$ when considering a column height of $1,000 \mathrm{~m}$. For PC2, drawpoints with the lowest extraction (2\%) are in the northeast area, representing a maximum of $15-30 \mathrm{~m}$ of extracted column. The mean extraction from the block is $6.1 \% \pm 3 \%$.

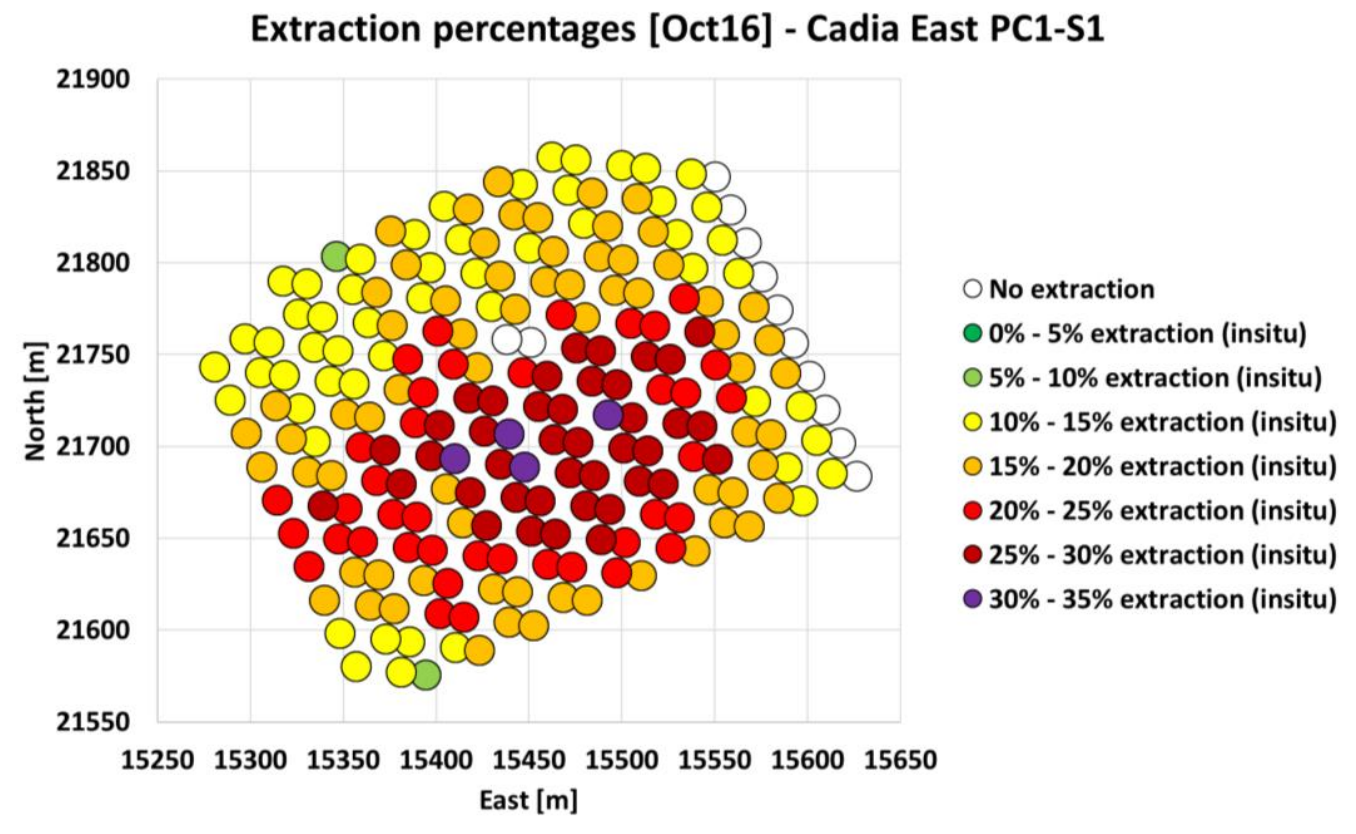

Figure 6 Extraction percentages per drawpoint - PC1-S1

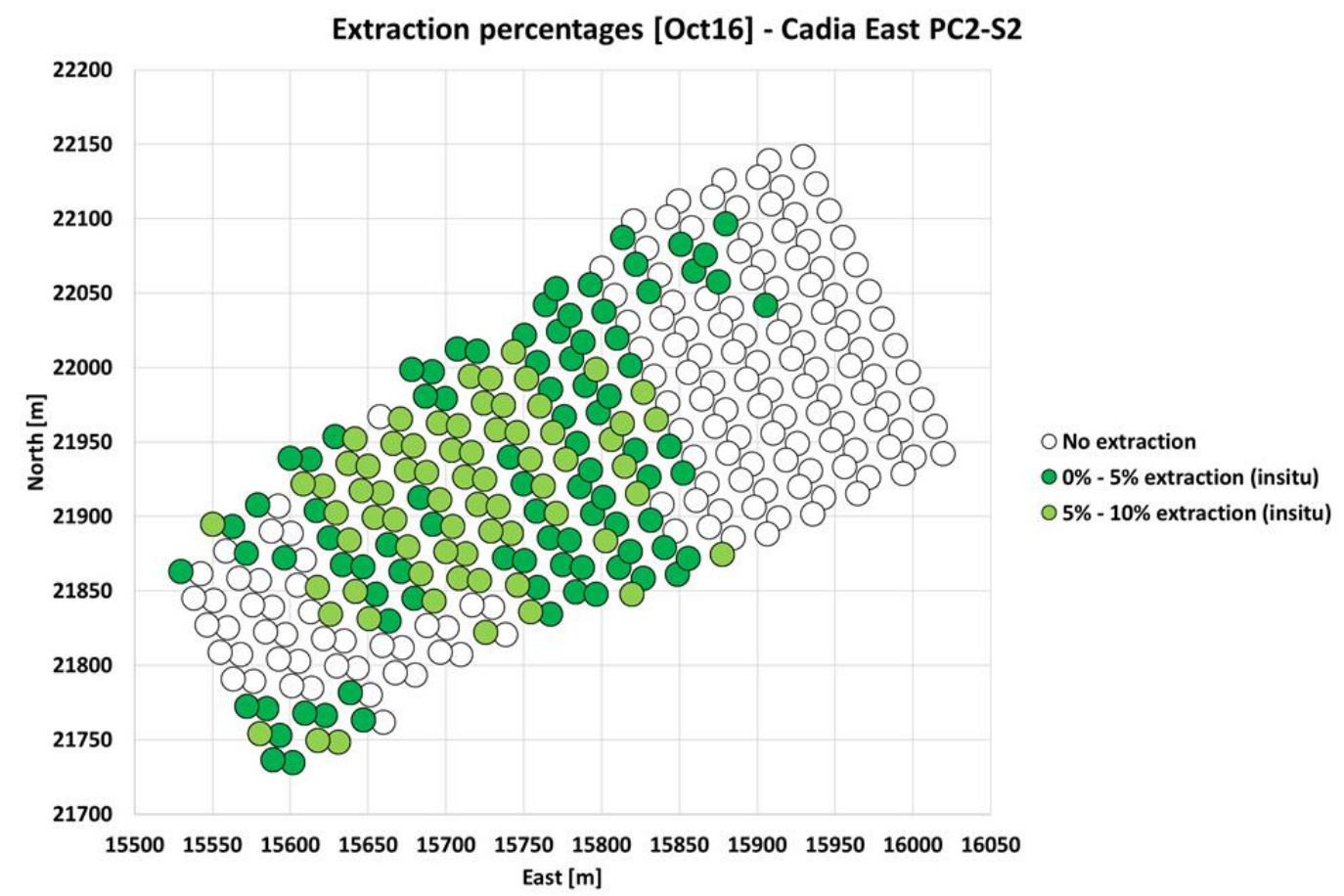

Figure 7 Extraction percentages per drawpoint - PC2-S2 
Figure 8 shows the relation between $\mathrm{d}_{80}$ (characteristic size) and percentage extraction in drawpoints that have at least one measurement of fragmentation for PC1-S1. Before $14 \%$ of extraction, where the caving did not connect with the surface, the mean size was $0.62 \mathrm{~m} \pm 0.3 \mathrm{~m}$ (medium-coarse). After the caving breakthrough to surface, the size reduced to $0.44 \mathrm{~m} \pm 0.1 \mathrm{~m}$ (reduction of $30 \%$ in size). This may be due to the influence of the cave load acting on the ore column, which further induced secondary fragmentation within the cave.

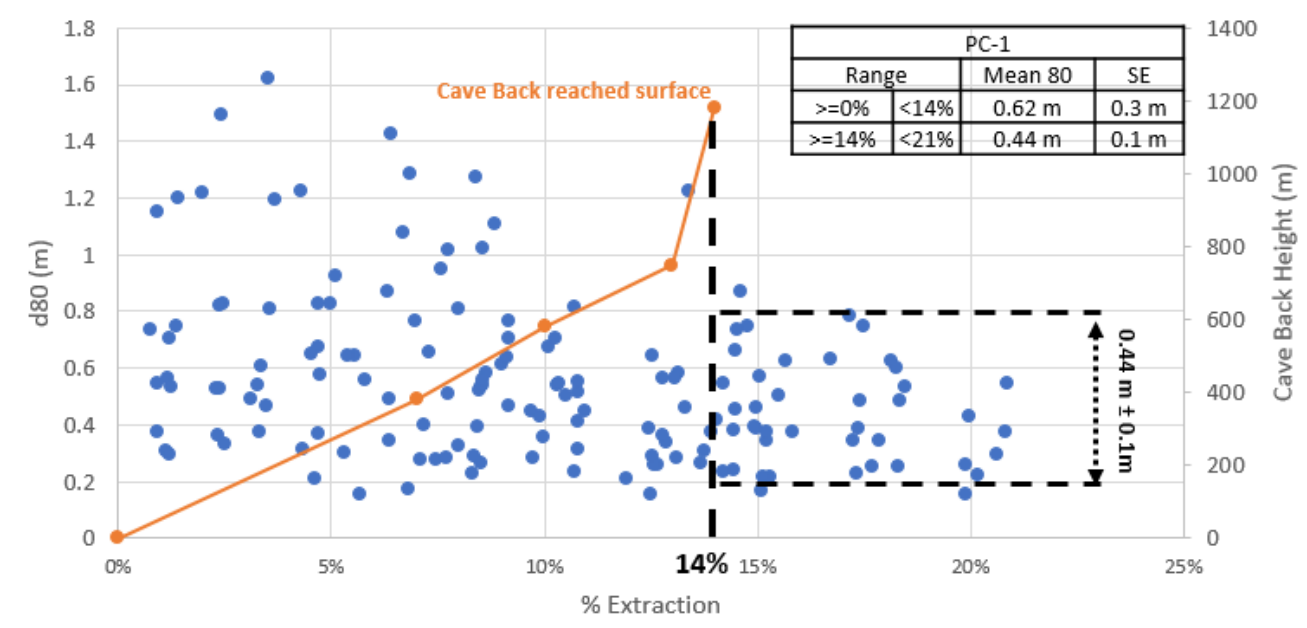

Figure 8 Relationship $\mathrm{d}_{80}$ versus percentage extraction for drawpoints with measurement at PC1-S1

Figure 9 shows the relation between $d_{80}$ and percentage extraction in drawpoints that have at least one measurement of fragmentation for PC2-S1. The average $d_{80}$ is $0.72 \mathrm{~m} \pm 0.46 \mathrm{~m}$. In contrast to the results obtained in PC1-S1, no significant change in fragmentation with extraction was noted. The reason for this could include:

1. In PC2, cave breakthrough to the surface has not occurred yet and has, as of 2017 , a smaller amount of mass drawn.

2. Differences in the rock mass.

3. Differences in the preconditioning applied to block PC2-S1.

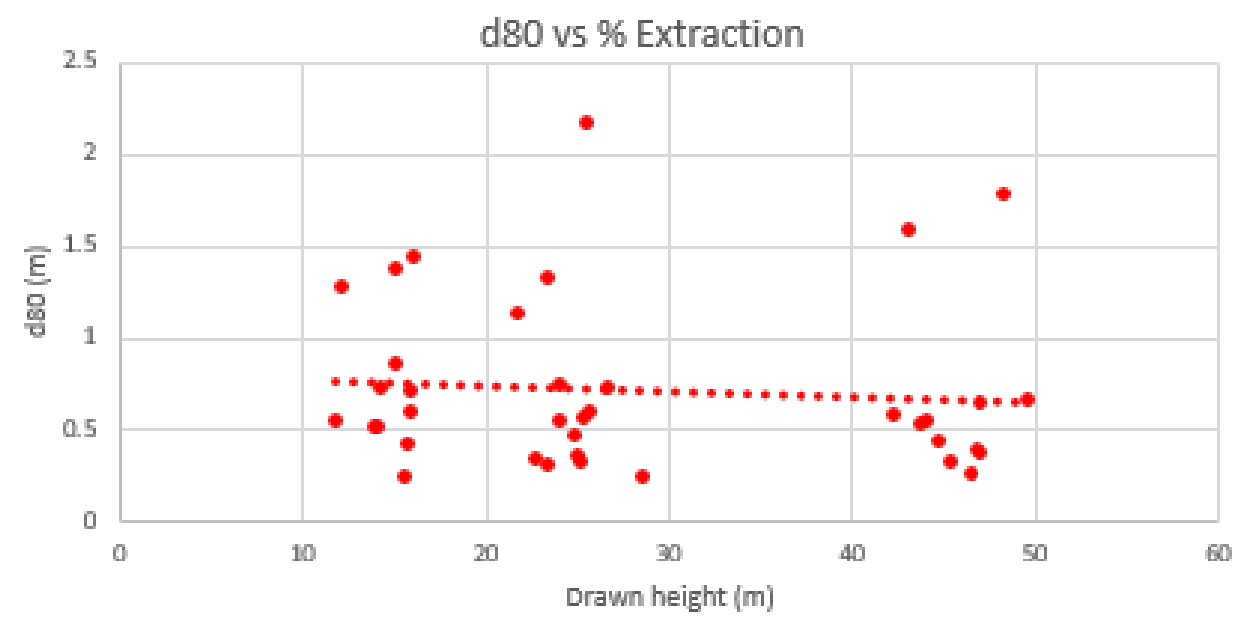

Figure 9 Relationship $\mathrm{d}_{80}$ versus percentage extraction for drawpoints with measurement at PC2-S1 
Figures 10 and 11 show the relationship between HUR and height of draw (HOD) (m) for PC1-S1 and PC2-S1. For PC1, the results show that as the HOD increases, the HUR decreases, reaching an average of $0.2 \pm 0.57$ events $/ 1,000 \mathrm{t}$ at $360 \mathrm{~m}$ of extraction. For the range of 40 to $160 \mathrm{~m}$, the HUR has a large dispersion, reaching values below HUR $=1$ event $/ 1,000 \mathrm{t}$.

In the case of PC2-S1, it can be observed that after $40 \mathrm{~m}$ of draw height, there is a continuous decrease of the HUR. In general terms, for the first $40 \mathrm{~m}$ of draw height, the HUR was $0.56 \pm 1.17$ events $/ 1,000 \mathrm{t}$, while after $40 \mathrm{~m}$ of draw height, the HUR was $0.4 \pm 0.43$ events $/ 1,000 \mathrm{t}$.

\section{Events/1,000 t vs Drawn Height - PC1}

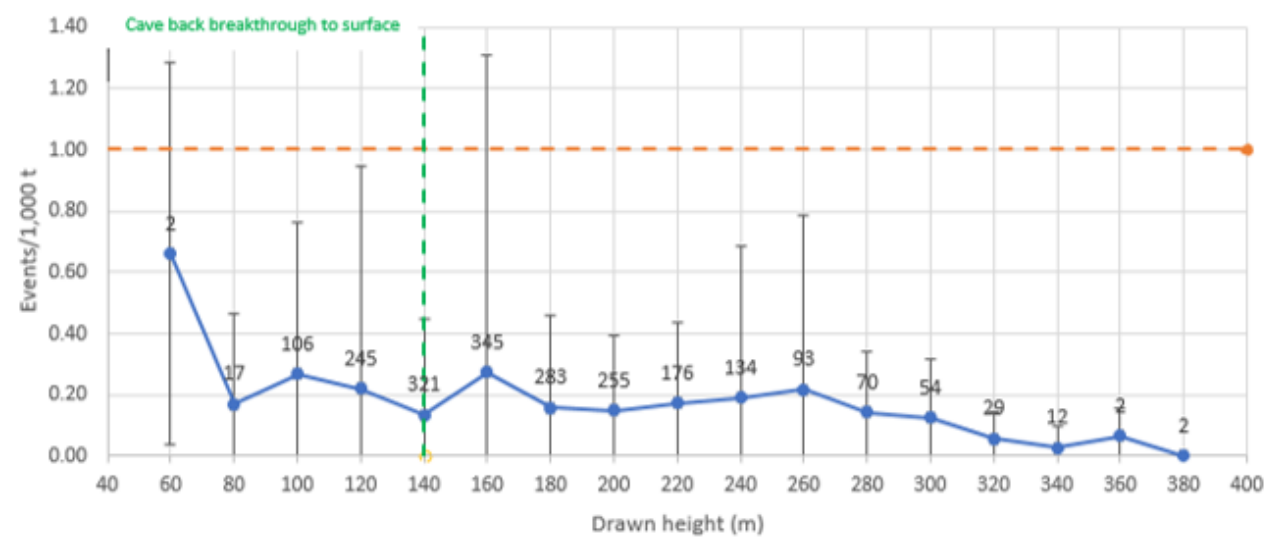

Figure 10 Relationship between HUR and HOD, quantity of data shown - PC1-S1

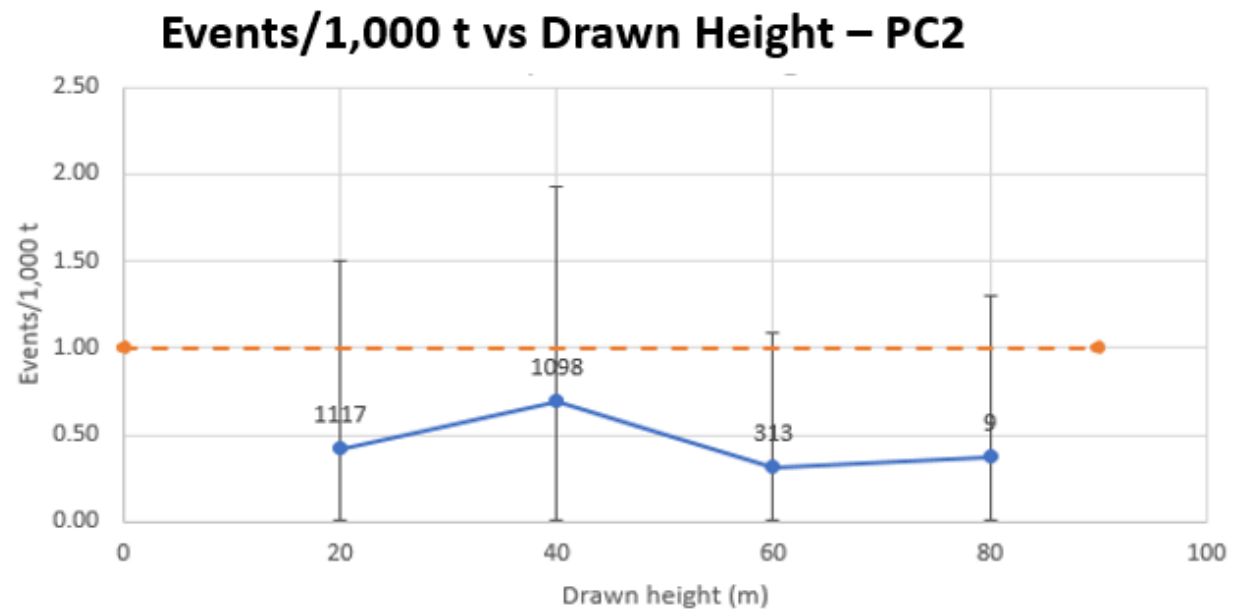

Figure 11 Relationship between HUR and HOD, quantity of data shown - PC2-S1

A summary of the analysis for the PC1-S1 and PC2-S1 performance up to 2017 is summarised in Table 2. As shown, there are significant differences in the two panels to date. 
Table 2 Summary of statistical analysis for PC1-S1 and PC2-S1 at 2017

\begin{tabular}{|c|c|c|}
\hline Parameter & PC1-S1 & PC2-S1 \\
\hline $\begin{array}{l}\text { Draw rate and } \\
\text { height } \\
\text { connection }\end{array}$ & $\begin{array}{l}\text { This sector has connected to surface and } \\
\text { is a mature cave with the following } \\
\text { statistics for drawpoints: } \\
\text { - Height of draw: } 226 \mathrm{~m} \pm 77 \mathrm{~m} \\
\text { - } \quad \text { Extracted tonnage: } \\
195 \text { ktonne } \pm 66 \text { ktonne } \\
\text { - Percentage extraction (total): } 23 \% \pm 8 \% \\
\text { - Preconditioning: hydraulic fracturing } \\
\text { and DDE } \\
\text { - Undercutting height: } 18-20 \mathrm{~m} \text { (post } \\
\text { undercutting) }\end{array}$ & $\begin{array}{l}\text { This sector at } 2017 \text { has not connected to } \\
\text { surface with the following statistics for } \\
\text { drawpoints: } \\
\text { - HOD: } 45 \mathrm{~m} \pm 22 \mathrm{~m} \\
\text { - } \quad \text { Extracted tonnage: } \\
39 \text { ktonne } \pm 19 \text { ktonne } \\
\text { - Percentage extraction (total): } 6 \% \pm 3 \% \\
\text { - Preconditioning: hydraulic fracturing } \\
\text { - Undercutting height: } 18-20 \mathrm{~m} \text { (post } \\
\text { undercutting and advance } \\
\text { undercutting) }\end{array}$ \\
\hline Fragmentation & $\begin{array}{l}\text { PC1 started slowly, and continuously } \\
\text { increased the draw rate from } 0.4 \mathrm{t} / \mathrm{m}^{2} / \text { day } \\
\text { to } 0.9 \mathrm{t} / \mathrm{m}^{2} / \text { day as the cave back } \\
\text { breakthrough to surface occurred. } \\
\text { Fragmentation has reduced with extraction. } \\
\text { At HOD }=140 \mathrm{~m} \text { ( } 14 \% \text { extraction), the } \mathrm{d}_{80} \\
\text { reduced from } 0.62 \mathrm{~m} \pm 0.3 \mathrm{~m} \text { to } 0.44 \mathrm{~m} \pm \\
0.1 \mathrm{~m} \text {, which is consistent with caving } \\
\text { reaching the surface. The variability or range } \\
\text { of the fragment size also decreased after } \\
\text { caving connection. }\end{array}$ & $\begin{array}{l}\text { PC2 started with a draw rate of } \\
0.25 \mathrm{t} / \mathrm{m}^{2} / \text { day and increased to } \\
0.5 \mathrm{t} / \mathrm{m}^{2} / \text { day after reaching } 100 \mathrm{~m} \text { of draw } \\
\text { height. } \\
\text { The } \mathrm{d}_{80} \text { at } 50 \mathrm{~m} \text { of draw height }(7-8 \% \\
\text { extraction) reaches } 0.72 \mathrm{~m} \pm 0.46 . \\
\text { Fragmentation has stayed constant } \\
\text { (medium-coarse) showing some tendency } \\
\text { to reduce with the increase of HOD. }\end{array}$ \\
\hline HUR & $\begin{array}{l}\text { The HUR for PC1 is very small, showing } \\
\text { values below } 1 \text { and decreasing with } \\
\text { extraction to } 0.2 \pm 0.8 \text { (for HOD }>40 \text { and } \\
\text { below 200) and } 0.1 \pm 0.5 \text { (for HOD > } \\
400 \mathrm{~m} \text { ). This is consistent with the } \\
\text { observation of finer fragmentation } \\
\text { reaching the drawpoints as the HOD } \\
\text { increased. HUR has not been an issue in } \\
\text { terms of flow interferences in PC1. }\end{array}$ & $\begin{array}{l}\text { The statistical analysis for HUR at PC2 } \\
\text { indicates that: } \\
\text { - The HUR decreases with extraction. } \\
\text { - For HOD }>20 \text { m the HUR is lower on } \\
\text { pre-undercutting than in } \\
\text { post-undercutting. There is not } \\
\text { enough information on HUR to make } \\
\text { conclusions about HUR for higher } \\
\text { HOD. } \\
\text { There is a decrease of HUR as the } \\
\text { draw is more uniform. } \\
\text { There is an increase of HUR as the } \\
\text { rock mass rate (RMR) increases. }\end{array}$ \\
\hline Lithology & $\begin{array}{l}\text { For HOD }<160 \mathrm{~m} \text {, the HUR for the } \\
\text { monzonite was } 0.57 \pm 1.48 \text { events } / 1,000 \mathrm{t} \text {, } \\
\text { while for the volcanic rock, it was } 0.14 \pm \\
0.34 \text { events } / 1,000 \mathrm{t} \text {. For } \mathrm{HOD}>160 \mathrm{~m} \text {, the } \\
\text { HUR for the monzonite was } 0.18 \pm 0.38 \text {, } \\
\text { and the volcanics } 0.12 \pm 0.24 \text { respectively. }\end{array}$ & $\begin{array}{l}\text { For } \mathrm{HOD}<80 \mathrm{~m} \text {, the HUR in the volcanics } \\
\text { was } 0.54 \pm 1.16 \text { events } / 1,000 \mathrm{t} \text {, while for } \\
\text { monzonite rock, it was } 0.49 \pm 1.04 \\
\text { events } / 1,000 \mathrm{t} \text {. The tendency is different } \\
\text { than what was observed in PC1-S1. }\end{array}$ \\
\hline
\end{tabular}




\section{$4 \quad$ BCRisk $^{\circledR}$ modelling - application to PC2}

BCRisk is a risk analysis tool which quantifies the risks associated with the extraction process in caving mines (dilution, wet muck and hang-ups). Figure 12 shows the BCRisk methodology applied in the present study. The most important step in the methodology is database building, which considers the sampling methodology shown by Hosmer et al. (2013). This database contains information including percentage extraction accumulated, monthly extracted tonnage, events/1,000 t, type of lithology, RMR, and uniformity index of draw.

As shown in Figure 11, BCRisk would give the probability $P(H U R>1$ event $/ 1,000 t)$ and the number of events for a given production plan. The predictive results of having over 1 event/1,000 t were compared with the actual number of drawpoints with HUR $>1$. In terms of the analysis, the first $20 \mathrm{~m}$ of column were not considered because this would correspond to the undercutting blast. The regression analysis and fitting were performed using the software SPSS (IBM 2018), which is widely applied in other disciplines (Hosmer et al. 2013).

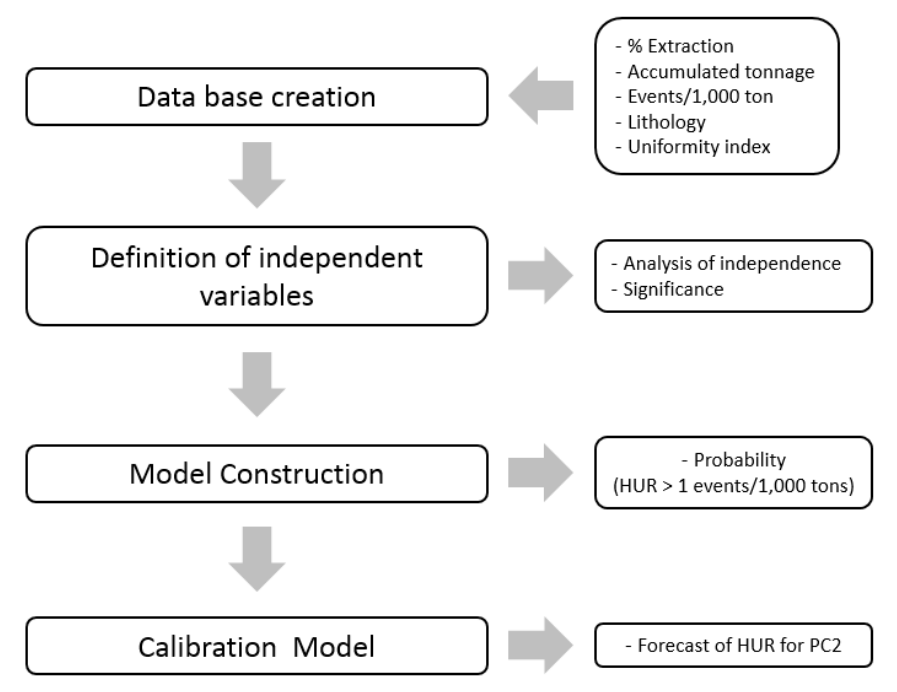

Figure 12 BCRisk methodology

\subsection{Univariate analysis of hang-ups}

Once the database was built, the first step was to define the main variables that influence the occurrence of hang-ups. The variables that were analysed are shown in Table 3.

Table 3 Variables analysed for PC2

\begin{tabular}{|c|c|}
\hline Variable & Definition \\
\hline $\mathrm{HOD}(\mathrm{m})$ & Corresponds to the equivalent height of draw per drawpoint \\
\hline $\begin{array}{l}\text { Uniformity } \\
\text { index (\%) }\end{array}$ & $\begin{array}{l}\text { Corresponds to the uniformity index in terms of percentage of total } \\
\text { mass drawn in a given month. The daily draw is classified according } \\
\text { to the uniformity index as uniform or not uniform, respectively }\end{array}$ \\
\hline RMR & Corresponds to the RMR number observed at the production level \\
\hline Lithology & Corresponds to the lithology observed at the production level \\
\hline
\end{tabular}


The uniformity index was calculated by (Susaeta 2004):

$$
\text { I. } U=\Delta+\tau * \frac{\left(t_{p}-t_{\min }\right)}{t_{\max }{ }^{2} * n} \sum_{i=1}^{n}\left(t_{\max }-t i\right)
$$

where:

$$
\begin{aligned}
& \Delta \quad=\text { number of inactive neighbours. } \\
& \tau \quad=\text { normalisation factor equal to 99/89. } \\
& t_{p} \quad=\text { tonnage extracted from the drawpoint in a given day. } \\
& t_{i}=\text { tonnage extracted from drawpoint } i \text { belonging to the vicinity of the drawpoint in a given day. } \\
& t_{\max }=\text { maximum tonnage drawn from the vicinity of the drawpoint in the same period. } \\
& t_{\min }=\text { minimum tonnage drawn from the vicinity of the drawpoint in the same period. } \\
& \mathrm{N} \quad=\text { number of points belonging to the neighbourhood of the drawpoint. }
\end{aligned}
$$

\begin{tabular}{|c|c|c|c|c|}
\hline Variables & $(\beta)$ & Significance & Odds ratio & Example of significance \\
\hline \multirow{2}{*}{$\mathrm{HOD}(\mathrm{m})$} & \multirow{2}{*}{-0.062} & \multirow{2}{*}{$7 * 10^{-7}$} & \multirow{2}{*}{0.94} & $\begin{array}{l}\text { A draw height increase of } 10 \mathrm{~m} \text { (from } 10 \text { to } 20 \mathrm{~m} \text { ) would } \\
\text { increase in } 26 \% \mathrm{P}(\mathrm{HUR}>1 \text { events } / 1,000 \mathrm{t})\end{array}$ \\
\hline & & & & $\begin{array}{l}\text { A draw height increase of } 20 \mathrm{~m} \text { (from } 20 \text { to } 30 \mathrm{~m} \text { ) would } \\
\text { increase in } 50 \% \mathrm{P}(\mathrm{HUR}>1 \text { events } / 1,000 \mathrm{t})\end{array}$ \\
\hline RMR & 0.035 & 0.008 & 1.03 & $\begin{array}{l}\text { An increase on the RMR index from } 50 \text { to } 60 \text { would } \\
\text { increase in } 30 \% P(H U R>1 \text { events } / 1,000 t)\end{array}$ \\
\hline $\begin{array}{l}\text { Uniformity } \\
\text { index (\%) }\end{array}$ & -0.605 & 0.04 & 0.54 & $\begin{array}{l}50-80 \% \rightarrow 13 \% \text { hang-up probability } \mathrm{P}(\mathrm{HUR}>1 \\
\text { events } / 1,000 \mathrm{t})\end{array}$ \\
\hline Lithology & - & 0.232 & - & $\begin{array}{l}\text { Due to its low significance value, this variable should not } \\
\text { be included in the modelling }\end{array}$ \\
\hline
\end{tabular}

The univariate analysis of hang-up rate for Cadia PC2-S1 is shown in Table 4. As shown, lithology was found to be insignificant in terms of $\mathrm{P}(\mathrm{HUR}>1)$.

Table 4 Results of univariable analysis on PC2-S1 data

\subsection{Multivariate modelling}

The next step was to build a multivariable model for hang-ups. This model gives an idea of the link between the main variables. The adjustment indicates that:

$$
P(H U R>1)=\frac{\exp (0.035-0.059 H O D+0.02 \cdot R M R-0.59 \cdot U I)}{1+\exp (0.035-0.059 H O D+0.02 \cdot R M R-0.59 \cdot U I)}
$$

where:

$$
\begin{aligned}
& \mathrm{HOD}=\text { height of draw }(\mathrm{m}) . \\
& \mathrm{RMR}=\text { rock mass rating. } \\
& \mathrm{UI}=\text { uniformity index }(\%) .
\end{aligned}
$$

The $\mathrm{P}(\mathrm{HUR}>1)$ was compared for the hang-ups database of $\mathrm{PC1}$ (which considered extraction during 2016). In this case, the cutoff probability was set to 0.25 . This means that if $P(H U R)>25 \%$, the drawpoint is expected to have more than 1 event/1,000 drawn tonnes. As shown in Figure 13, for April 2016 the model predicts 21 drawpoints with $>1$ event/1,000 $t$ while the mine database shows one drawpoint. However, in May 2016 
the model predicts 21 drawpoints with $>1$ event/1,000 t while the database shows 17 drawpoints, which represents about $81 \%$ accuracy.

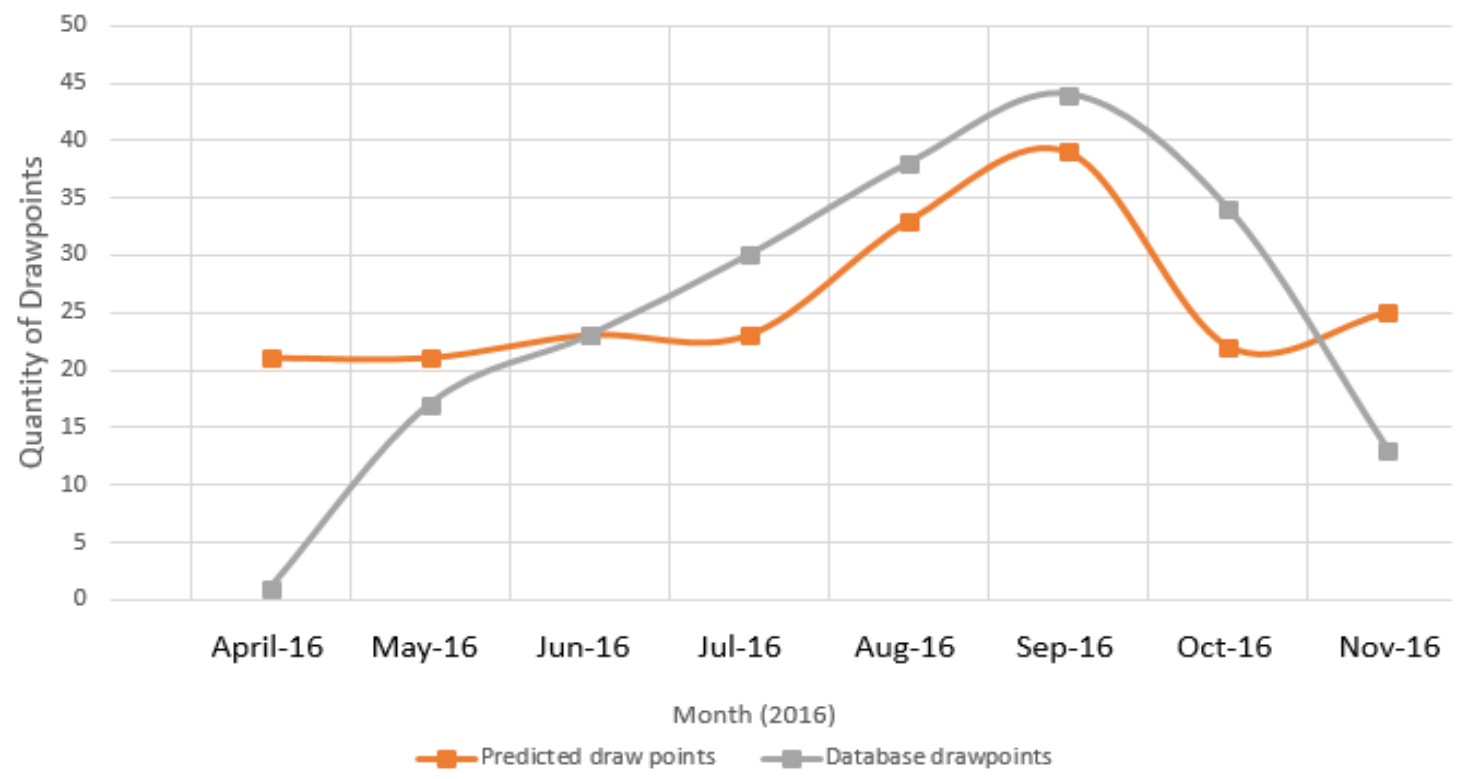

Figure 13 Number of drawpoints with more than 1 event/1,000 extracted tonnes

The results of $P(H U R)$ could be observed in a plan view. As shown in Figure 14, a high probability indicated a larger number of events.

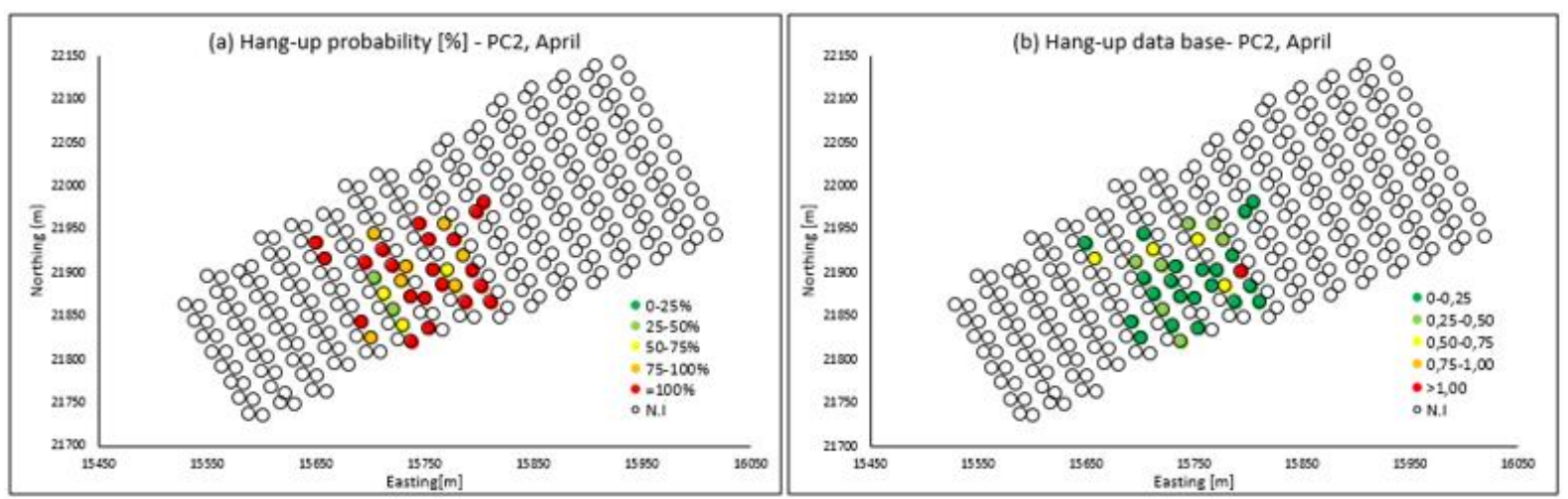

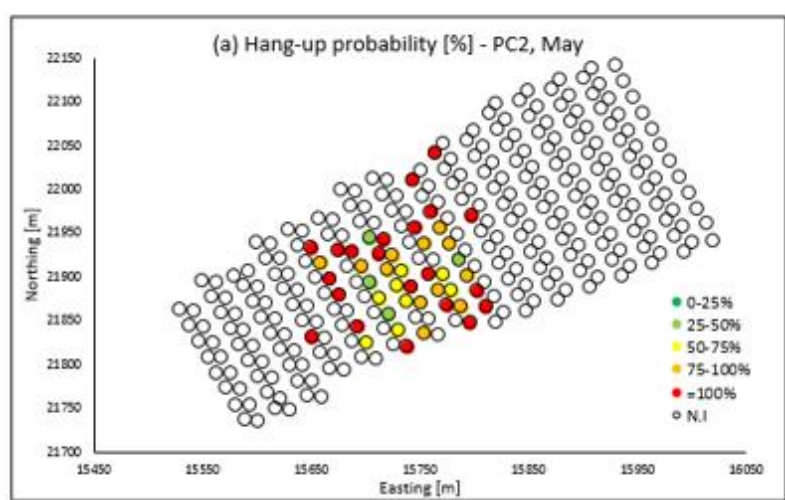

(a)

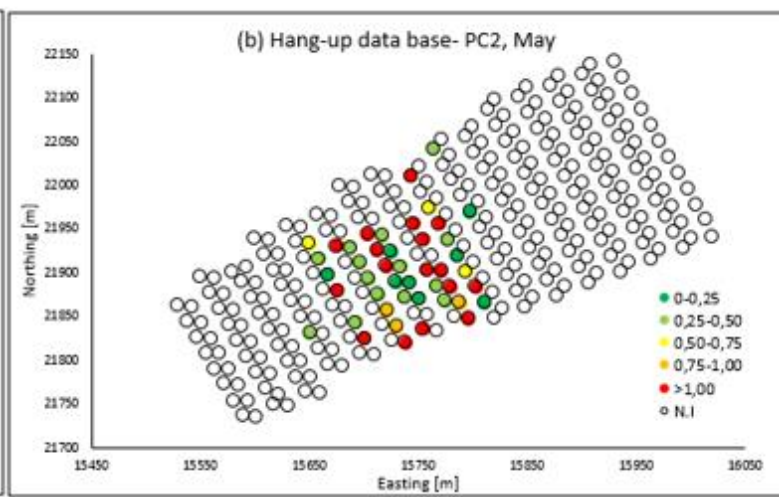

(b)

Figure $14 \mathrm{P}(\mathrm{HUR})$ and (a) actual HUR; and, (b) database for April and May 2016. Red dots indicate drawpoints with a large number of events 
The $P(H U R)$ was linked to the observed number of events, as shown in Figure 15. In this, the actual number of observed events and the calculated probability monthly is shown. The tendency is that the larger the $\mathrm{P}(\mathrm{HUR})$, the larger the observed number of events. Therefore, $\mathrm{P}(\mathrm{HUR})$ could be used to predict the number of events for a given production plan.

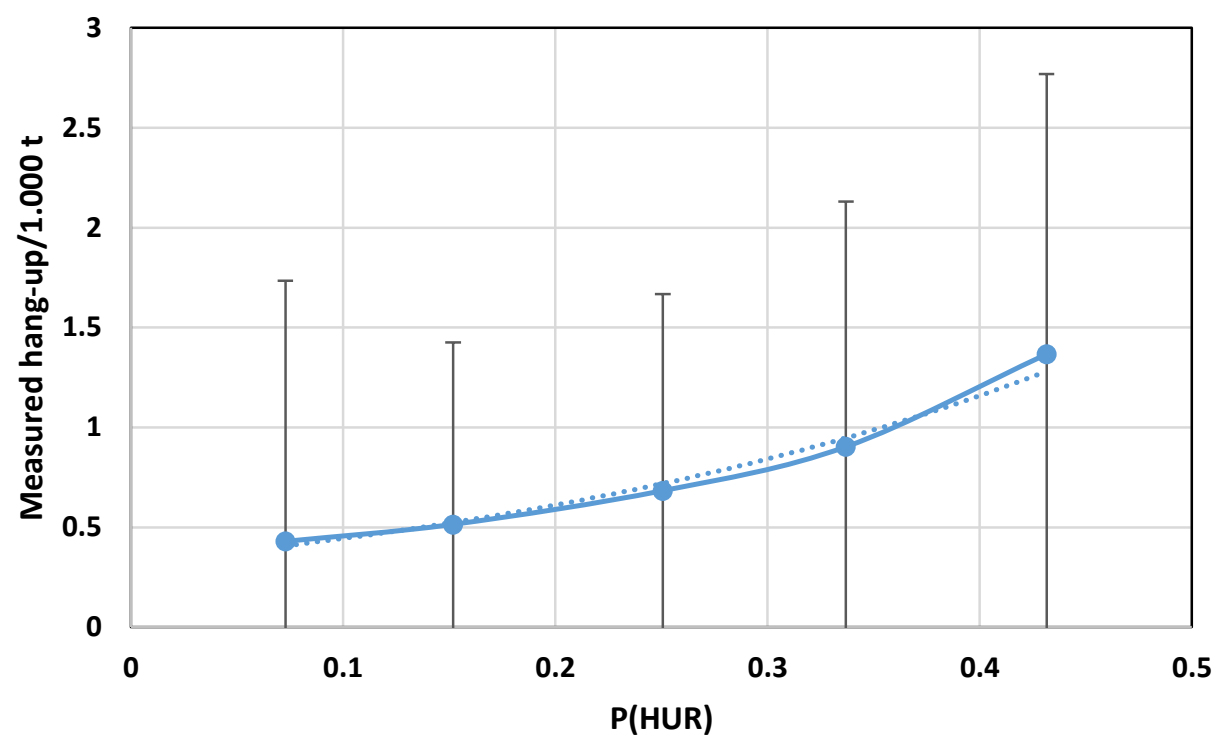

Figure 15 Measured and calculated P(HUR) for PC2-S1.

\section{Conclusion}

The main conclusions of this study are the following:

- PC1 and PC2 have behaved differently in terms of fragmentation and hang-ups. A major difference is that PC1 is a mature cave that has connected to the surface and had a different type of preconditioning.

- The information to date on PC2 indicates that PC1 has a smaller HUR than PC2 (at least for $H O D=70 \mathrm{~m}$ ). This could be due to the different preconditioning techniques used in the panels.

- It is expected that PC2 fragmentation and HUR will reduce as more draw is conducted and the cave connects to the surface.

- Regression analysis techniques were found to be useful for hang-up modelling at PC2 in terms of determining the main variables and to predict the expected number of events. The main variables were found to be RMR, HOD and uniformity index. In terms of accuracy, an $81 \%$ accuracy was achieved. This model could be improved and be useful for planning purposes as more production data is collected and analysed in the future.

\section{Acknowledgement}

The authors acknowledge those people involved in this study. First, we thank Mr Alvaro Altamirano and Luis Araya for their contribution to this work. We also thank James Lett from Cadia for discussions during this study. Finally, David Cuello thanks CVO for allowing us to present the results of this study. 


\section{References}

Arancibia, L, Castro, R, Valencia, M \& Cifuentes, M 2018, 'Modelling of early dilution entry using regression techniques', in R Castro \& Y Herazo (eds), Proceedings of UMining2018, Universidad de Chile Santiago, Santiago, pp. 65-81, in Spanish.

Brunton, I, Lett, J \& Thornhill, T 2016, 'Fragmentation prediction and assessment at the Ridgeway Deeps and Cadia East cave operations', in C Carr \& G Chitombo (eds), Proceedings of MassMin 2016, The Australasian Institute of Mining and Metallurgy, Melbourne, pp. 151-160.

Brzovic, A, Vallejos, J, Arancibia, E, Burgos, L, Delonca, A, Gaete, M \& Barrera, V 2016, 'Analysis and modelling of the fragmentation process - Case studies at El Teniente Mine', in C Carr \& G Chitombo (eds), Proceedings of MassMin 2016, The Australasian Institute of Mining and Metallurgy, Melbourne, pp. 305-310.

Hosmer, DW, Lemeshow, S \& Sturdivant, RX 2013, Applied Logistic Regression, 3rd edn, John Wiley \& Sons, New Jersey.

IBM 2018, SPSS, computer software, IBM, Armonk, https://www.ibm.com/analytics/spss-statistics-software

Kvapil, R 2008, Gravity Flow in Sublevel and Panel Caving - A Common Sense Approach, Luleå University of Technology, Luleå.

Laubscher, D 1994, 'Cave mining - the state of art', Journal of South African Institute of Mining and Metallurgy, vol. 94, no. 10, pp. 279-293.

Lett, J 2016, PC2-S1 Rock Mass Model - Summary Report, Newcrest Mining Limited, Melbourne.

Lett, J, Brunton, I, Capes, GW, Jäger, A, Mobilio, B, Rachocki, J, Sharrock, GB \& Secheny, M 2016, 'Undercutting to surface breakthrough - Cadia East Panel Cave (Stage 1)', in C Carr \& G Chitombo (eds), Proceedings of MassMin 2016, The Australasian Institute of Mining and Metallurgy, Melbourne, pp. 65-82.

Lett, J \& Rossimel, C 2012, Cadia East Geotechnical Block Model for PC1-S1, Newcrest Mining Limited, Melbourne.

Lowther, RJ, Olivier, L, Lett, JL \& Brunton, I 2016, 'Implementation of a surface-based hydraulic fracturing program to successfully propagate a large cave through hard, competent near-surface rock masses to achieve breakthrough', in C Carr \& G Chitombo (eds), Proceedings of MassMin 2016, The Australasian Institute of Mining and Metallurgy, Melbourne, pp. 83-96.

Lopez, S 2016, Experimental Study of Hang-ups in Caving Mining, undergraduate thesis, University of Chile, Santiago, in Spanish.

Susaeta, A 2004, 'Theory of gravity flow (part 2)', in A Karzulovic and MA Alfaro (eds), Proceedings of MassMin 2004, Instituto de Ingenieros de Chile, Santiago, pp. 173-178. 
